\title{
The Pattern of the Mineralization of Enamel
}

\author{
JAMES K. AVERY, ROGER L. VISSER, and DONALD E. KNAPP
}

The University of Michigan School of Dentistry, Ann Arbor, Michigan

Voluminous literature on the subject of enamel mineralization has been reviewed and published recently. ${ }^{1,2}$ Therefore, the author will not attempt to cite again the numerous individual contributions of the many investigators in this area. An evaluation of the past studies leads the reader to the conclusion that at least two general concepts of enamel mineralization have been developed and appear in the literature today. One concept postulates that mineralization of the enamel follows the pattern of formation of the enamel matrix from the dentino-enamel junction peripherally. ${ }^{1-12} \mathrm{~A}$ second concept of enamel mineralization suggests that enamel matrix formation and final mineralization are separate processes, the latter not occurring until after the former is complete. ${ }^{13-22}$ This latter concept indicates that calcification of enamel matrix begins at the cusp tips and proceeds cervically in a direction perpendicular to that of incremental deposition of the matrix.

Textbooks ${ }^{23},{ }^{24}$ have adhered to the principles of the latter concept, stating that a primary influx of mineral salts occurs during matrix formation and that a secondary calcification process, in which three-quarters of the ultimate mineral content appears, occurs after matrix formation is complete. This secondary mineralization process, termed "maturation," is said to proceed non-incrementally from the tips of the cusps to the cervical region and at right angles to the long axis of the tooth.

Recently extensive investigations utilizing fluorescence and polarizing microscopy, ${ }^{1}$ electron microscopy, ${ }^{25,} 26$ isotopes, ${ }^{27,}{ }^{28}$ and microradiography, ${ }^{2,8-12}$ have revealed new and convincing evidence confirming the earlier beliefs ${ }^{3-5}$ that enamel is mineralized from the dentino-enamel junction peripherally in the same or a similar pattern as that of matrix production. A recent study of the birefringence of developing enamel ${ }^{29}$ has confirmed the microradiographic findings of a gradient of mineral concentration from the dentino-enamel junction peripherally. It is difficult, however, to evaluate the recent information in respect to whether or not total pre-eruptive mineralization has been accounted for. Whereas the autoradiographic and microradiographic techniques have shown clearly the relative distribution of mineral, they have not quantitatively assessed mineral content. These latest investigations have not, therefore, ruled out a secondary mineralization or maturation of enamel which has been postulated from quantitative chemical analysis of developing enamel. ${ }^{18}$

The present studies were carried out in an effort to determine the amount and dis-

Parts of this investigation were reported before the I.A.D.R. and published in abstract form in the J. D. Res., 38:678, 1959, and 39:712, 1960.

This study was supported by the Research and Development Division, Office of the Surgeon General, Department of the Army, under contract No. DA-49-007-MD-909.

Received for publication January 12, 1961. 
tribution of mineral in all stages of enamel mineralization by using a combination of four techniques: microhardness tests, microradiography, microdissection, and microsubstitution..$^{30}$ It was believed that, by correlation of the findings from these methods, information would be gained concerning the processes involved in the mechanism of enamel mineralization and indicating whether or not there are two distinct stages in the calcification of enamel matrix.

\section{MATERIALS AND METHODS}

A group of 22 teeth was obtained at autopsy from four humans aged two and onehalf, three, four, and four and one-half years. Another series consisting of 34 developing teeth was taken from a group of six Rhesus monkeys, one to three years of age. The teeth were selected for study according to the extent of formation and calcification as observed by conventional radiographs (Fig. 1). After dissection from the jaws, the

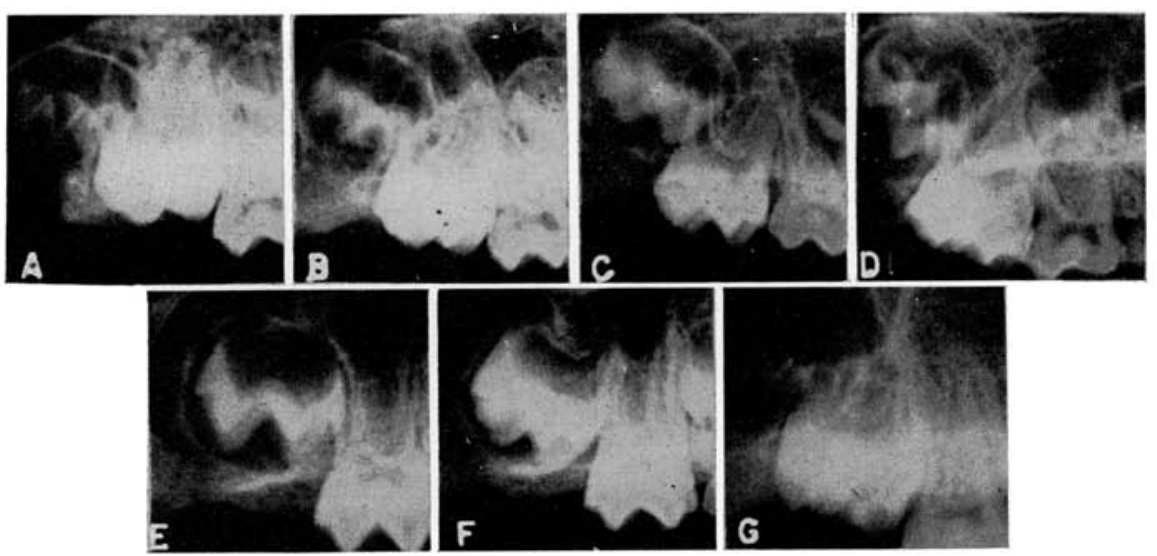

FIG. 1.-Radiographs of a representative series of monkey maxillary second permanent molars used in the study. They are arranged in developmental sequence from early stages of calcification of the cusps in $A$ to a stage of eruption through the alveolar bone in $G$.

developing crowns were photographed (Fig. 2) and then dehydrated, embedded in quick-setting plastic (to prevent infiltration), and bisected by means of a water-cooled cutting disk.* One half of each tooth was cut into serial sections of approximately 75 $\mu$ for microradiographic study. The thickness of each section was measured with a micrometer to determine the proper time of radiographic exposure for each sample. The thin sectoins were stored in distilled water until ready to be radiographed. They then were dried and placed in direct contact with spectroscopic plates. $†$ Microradiographs were taken at a voltage of $10 \mathrm{kv}$. This voltage gives $\mathrm{X}$-rays of a wave length of approximately $2.2 \mathrm{~A}$, which is the proper wave length for maximal absorption by the calcium ions. The sections were exposed to 30 milliamperes for 35-70 minutes, depending on the thickness of the section. The microradiographs were then developed in Kodak D-19 for five minutes at $68^{\circ} \mathrm{F}$. Negatives of the plates were prepared, and enlarged prints made for study.

* Gillings-Hamco Thin Sectioning Machine, Hamco Machines, Inc., Rochester, New York.

† Kodak Type 649-0. 
The other halves of the plastic-imbedded crowns were used for microhardness tests. These halves were cut into sections $\frac{1}{2} \mathrm{~mm}$. thick, affixed to plastic slides, and polished. The enamel then was tested for microhardness, * using a 25 -gm. weight. Only uniform indentations showing a diamond-shaped impression with the long axis seven times greater than the width were used. In each sample a sufficient number of hardness measurements were made so that all areas of the enamel were evaluated. This resulted in as few as 35 measurements on young teeth with limited areas of sufficient hardness for measurement to as many as 100-125 measurements on more mature teeth. To facilitate interpretation of the pattern of hardness of each crown, the tooth sections were projected so that a magnified tracing of each section was obtained, and zones exhibiting a range of 30 Knoop Hardness Numbers (KHN) then were outlined on these diagrams.

In another series, developing human and monkey teeth were studied by microdis-

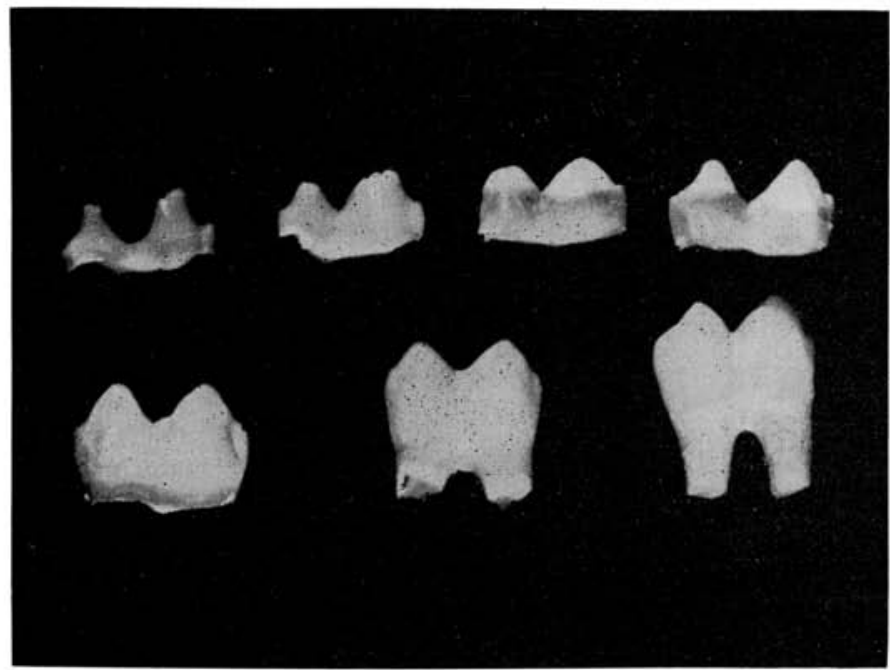

Fig. 2.-Photograph of the series of developing second molar crowns shown in Fig. 1, now dissected from the jaws. Observe the "formalin brown" (ref. 5) in contrast to the white enamel, which has led some authors to suggest the two-stage enamel development and calcification theories.

section and microsubstitution. ${ }^{30}$ These teeth were sectioned at $100-200 \mu$, placed in Soxhlet extractors, and extracted with 80 per cent ethylenediamine at $118^{\circ} \mathrm{C}$. for 72 hours. After extraction of organic matter they were washed with distilled water. One group of sections was immersed in water, and the enamel rods were dissected with finely drawn glass probes and studied under a stereomicroscope. The water was removed from the remaining organic-free sections in a $60^{\circ} \mathrm{C}$. oven. Then these sections were infiltrated under vacuum with an unsaturated polyester resin which filled the spaces formerly occupied by the organic matter and water. After the plastic had cured, the block was polished in order to expose the tooth section and was placed in $0.1 \mathrm{~N}$ hydrochloric acid to remove all mineral salts. After decalcification was complete, all that remained was a plastic skeleton which represented the location and relative concentration of organic material and water in the enamel and dentin and could be directly visualized and photographed.

* Tukon Microhardness Tester with a Knoop Diamond Indenter. 

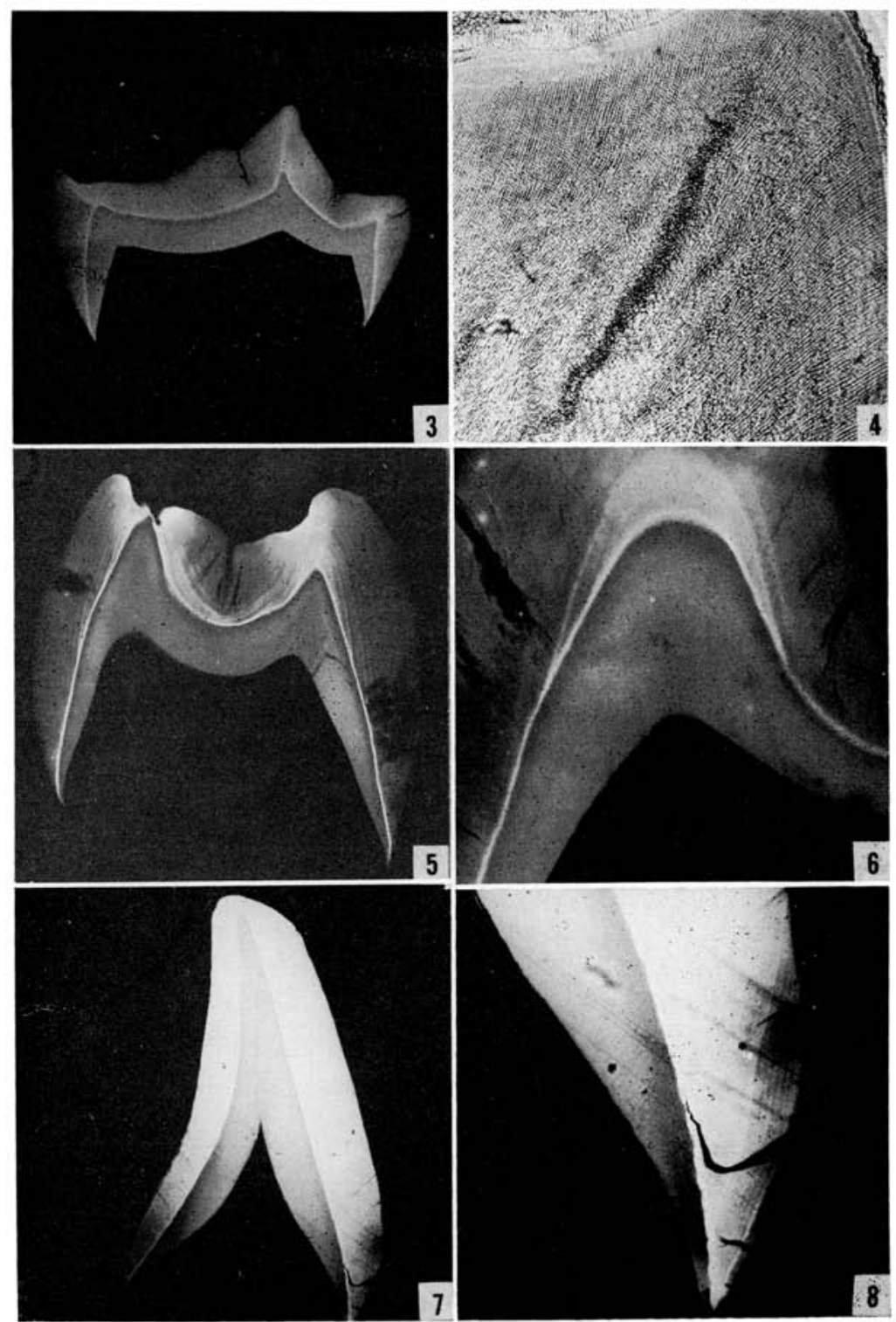

Figs. 3-8.-Fig. 3: Microradiograph of mesiodistal section of young monkey molar teeth illustrating the radiodense line along the dentino-enamel junction and small radiopaque projections at the peaks of each cusp. (Orig. mag. $\times 13$.) Fig. 4: Transmitted-light photomicrograph of decalcified young enamel of a developing monkey molar, illustrating the rod pattern at the center of a cusp. The rows of cross-sectioned rods which appear dark in transmitted light correspond with the radiopaque zone seen in the preceding figure. (Orig. mag. $\times 150$.) Fig. 5: Microradiograph of a human molar at a more advanced stage of mineralization than that shown in Fig. 3. The incremental lines appear more radiopaque than the adjacent enamel matrix. The areas along the dentino-enamel junction and the tips of the cusps appear to be the most highly mineralized areas. Defects due to grinding the specimens thin can be seen at the tip of the left cusp. (Orig. mag. $\times 13$.) Fig. 6: Microradiograph of a human molar illustrating an area of increased mineral density peripheral to the dentinoenamel junction. This increase in mineral content appears to mask the incremental lines. (Orig. mag. $\times 60$.) Fig. 7: Microradiograph of a human incisor, illustrating a more advanced state of mineralization. The enamel in this specimen appears uniformly radiodense except at the cervical areas of the crown. (Orig. mag. $\times 13$.) Fig. 8: A higher magnification of the cervical area of the crown shown in Fig. 7, illustrating the advancing mineralization in an incremental or nearly incremental pattern. The increased density of the mineral has masked all but a few of the radiopaque incremental lines. (Orig. mag. $\times 40$.) 
A final series of eight human and eight monkey teeth was collected for the purpose of comparing pre-eruptive and posteruptive hardness. The pre-erupted human teeth were bony-impacted third molars with radiographic evidence of fully formed roots. It was presumed from this latter characteristic that the enamel of these teeth was calcified to its normal pre-eruptive extent. The series of human erupted teeth consisted of maxillary and mandibular first molars. The monkey pre-erupted teeth were maxillary and mandibular second molars, and the erupted teeth were maxillary and mandibular first molars. Each of the human and monkey molars was from a different subject. All the teeth were imbedded in plastic and then sectioned. Microhardness determinations were made in the same manner as for the first group of teeth.

\section{RESULTS}

Microradiography.-In the youngest human and monkey teeth studied by microradiography, only a narrow radiopaque line measuring $35-50 \mu$ in width could be seen along the dentino-enamel junction of the entire crown (Fig. 3). This narrow band, which is the first indication of enamel mineralization, appeared even in the more cervical regions of the crown, where the amount of matrix and the length of time that it had been deposited were much less than at the cusp tips. The next area of increase in mineral content was at the cusp tip, spreading laterally and peripherally from the narrow spike which extended at right angles from the dentino-enamel junction toward the tips of the enamel cusps. These radiodense spikes were found to be prominent in developing monkey enamel and to correlate with the enamel-rod orientation of the sharply pointed cusps of monkey teeth. In the exact center of each developing cusp two adjacent Schreger bands or groups of enamel rods curved toward each other, resulting in a row of rods sectioned in the transverse axis. A difference in X-ray absorption was seen along this row, as well as differences in optical light paths seen by transmitted light (Fig. 4). The effect was due, at least partially, to the morphology of the rod structure but also to an increase in mineral density, since X-ray absorption increased further in this area in slightly older cusps. In human teeth most cusps were not as pointed as those of monkey molars, so that the area of mineralization extending from the dentino-enamel junction appeared more gently curved (Fig. 5). Gradually, the incremental lines (lines of Retzius) appeared more highly mineralized than the adjacent matrix (Fig. 6). Further mineralization from the dentino-enamel junction peripherally then masked the incremental lines in the area of the cusp tips (Fig. 7). The same process of calcification occurred later in the more cervical portions of the developing crown (Fig. 8). During the early stages of calcification a high-magnification microradiograph revealed radiodense enamel rods and radiolucent interrod* substance. Measurement of this uncalcified area between the rods showed that it was wider in young, calcifying enamel than it was in more completely calcified enamel (Figs. 9 and 10).

Thus it would appear that mineralization of young developing enamel followed an incremental or nearly incremental pattern from the dentino-enamel junction peripherally, similar to the pattern of matrix deposition. The mineral did not appear to be limited to a certain number of increments behind matrix formation but appeared to

* The term "interrod" substance is preferred to "interprismatic" substance because the prismatic (eight-sided) shape of enamel rods has been disproved (see ref. 25). 
diffuse from the areas of oldest matrix into the younger matrix. Mesial cusps of all molar teeth studied appeared to be more advanced in development (i.e., more highly mineralized) than the distal cusps (Fig. 3).

Microradiographs of young, calcifying enamel matrix presented varied characteristics. For example, in some specimens alternate Schreger bands had different degrees of radiodensity. Other specimens showed areas of unexplained opacity or lucidity, perhaps due to pathology of the enamel. For microradiographic studies, the sections should be ground exactly plano-parallel. Since this is difficult, if not impossible, this factor could have accounted for most of the variations from the general pattern.

After the radiopaque incremental lines had become obscured, the enamel appeared uniformly radiopaque (Figs. 11 and 12). No further information on differences in mineral density of these teeth could be gained by microradiography, so the other halves of each of these teeth then were tested for microhardness.

Microhardness.- Of the entire series of human and monkey teeth that were micro-
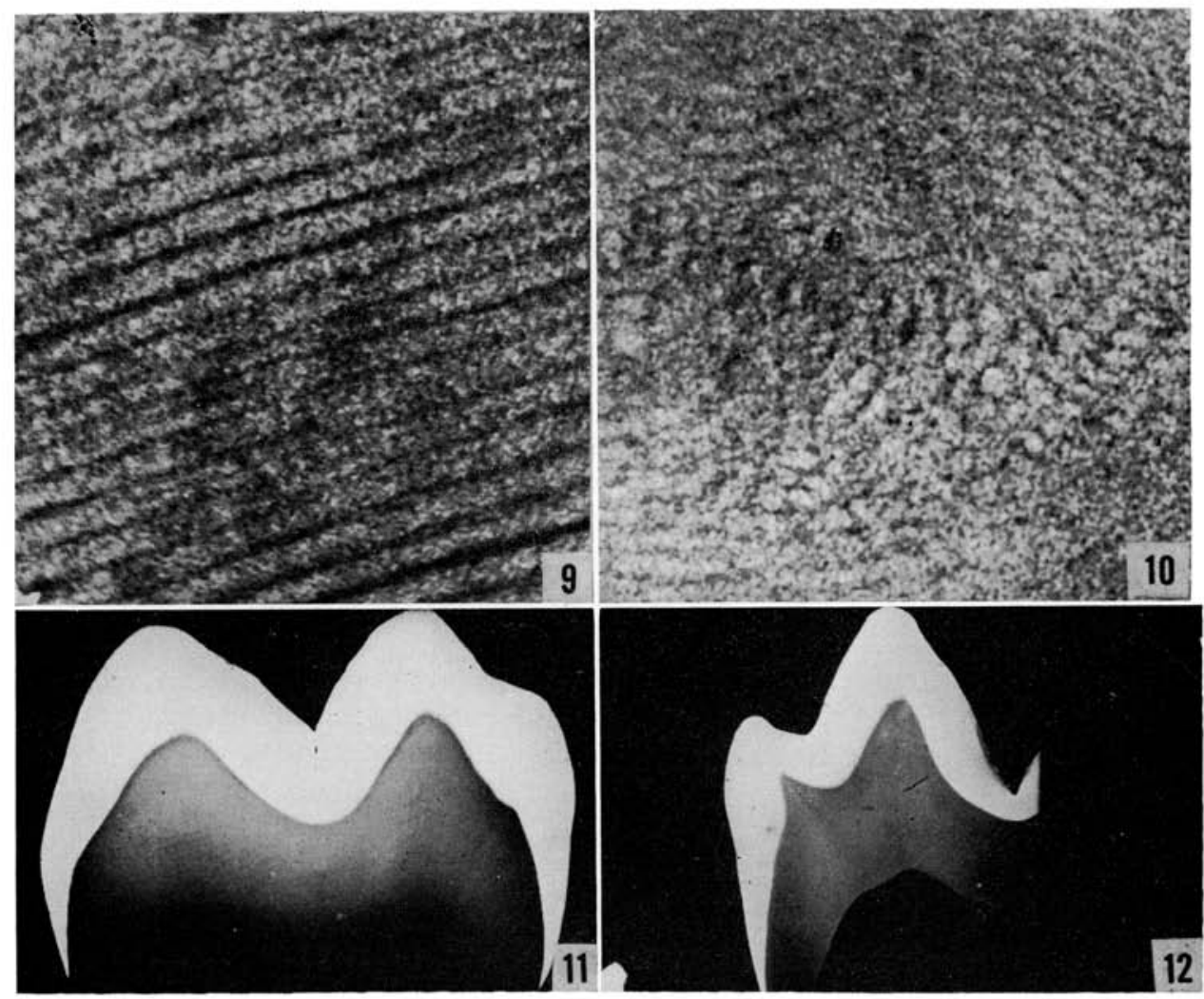

FIGs. 9-12.-Fig. 9: Microradiograph of young calcifying enamel matrix, illustrating the calcified rod substance in contrast to the non-calcified interrod substance. The microradiograph was magnified by means of photographic enlargement. (Orig. mag. $\times 200$.) Fig. 10: Microradiograph of older calcifying enamel matrix. Less radiolucent interrod substance is visible. The minute black dots in the photograph probably represent spaces between the more radiopaque groups of crystals. Test analysis of the spectroscopic plates revealed no grain size of this magnitude. (Orig. mag. $\times 600$.) Fig. 11: Microradiograph of the developing crown of a human molar which reveals a uniform distribution of mineral throughout the enamel. (Orig. mag. ×13.) Fig. 12: Microradiograph of the enamel of a monkey molar, revealing uniform radiodensity throughout. (Orig. mag. $\times 13$.) 
radiographed, only the oldest, uniformly radiopaque teeth were of sufficient hardness to gain accurate indentations with the Tukon Hardness Tester. Microradiographs obtained at $10 \mathrm{kv}$ and an exposure of 30 milliamperes for 35-70 minutes showed enamel to be uniformly radiopaque at a Knoop Hardness Number (KHN) of 100 or higher. It would appear that the microradiographs of mineralizing teeth used in this study revealed a distribution pattern of only a small amount of the total mineral if we consider that adult human enamel hardness is $343 \pm 23 \mathrm{KHN} .^{31}$ These observations are shown in microradiographs (Figs. 11 and 12) and in Figures 14 and 18, which represent hardness patterns of the same teeth.

The first areas of measurable hardness in both human and monkey enamel were along the dentino-enamel junction and in a narrow zone adjacent to this at the tips of the cusps. The $35-50 \mu$ band of enamel along the dentino-enamel junction had hardness values ranging from 150 to $280 \mathrm{KHN}$. This band was found to be consistently harder in the cusp than at the more cervical aspects of the crown. Fifty microns away from the dentino-enamel junction the enamel was too soft to be measured except in the region of the cusp tips (Fig. 13). No patterns indicating relative mineralization could be obtained on this tooth. Measurements at the cusp tip in a slightly more calcified tooth revealed hardness values decreasing from 280 to $30 \mathrm{KHN}$ as the indenter was moved toward the periphery of the cusp from the band along the dentino-enamel junction (Fig. 14).

The next tooth in the series was more advanced developmentally and exhibited a greater range of microhardness values. Although the band of mineralized enamel at the dentino-enamel junction was similar in hardness to that of the previous tooth, a great deal more mineral was apparent peripheral to this band. In this sample the hardness values ranged from $270 \mathrm{KHN}$ to very soft areas of $0-30 \mathrm{KHN}$ at the cervical area of the crown (Fig. 15). The map of the nine zones of decreasing hardness values presents an incremental appearance of mineral distribution in the developing crown very similar to the incremental pattern of matrix formation. It should be remembered that these zones pertain only to 30 -KHN ranges of microhardness and are not based on demonstrable morphologic divisions of enamel matrix such as those separated by the incremental lines of Retzius.

A study of other crowns followed, in which the hardness values were found to range from 0 to $400 \mathrm{KHN}$ (Figs. 16 and 17). In these crowns, zone 1 was comparable in hardness to the hardest areas found in adult enamel. Again the hardness values decreased from the dentino-enamel junction to the surface of the tooth following the chronologic incremental pattern of matrix formation. These mineralizing teeth illustrated the maximum range in hardness of enamel found in this study and thus show the greatest number (10) of zones of hardness.

In the next older specimen the range of microhardness values decreased as the size of the areas within the range of adult hardness increased (Fig. 18). The hardest areas, located at the cusp tips, were found to be uniformly mineralized. The less hard areas, located in the grooves between the cusps and at the cervical region of the crown, still exhibited an incremental pattern of hardness, although no areas of less than 90 KHN were found.

Following this, a specimen was selected which was in the process of eruption but had not emerged into the oral cavity. The measurements indicated that all areas of the 


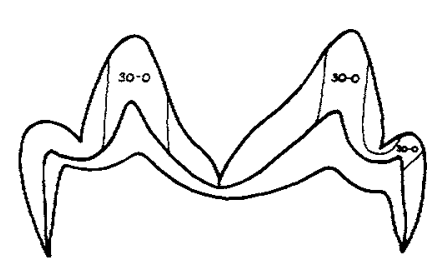

13
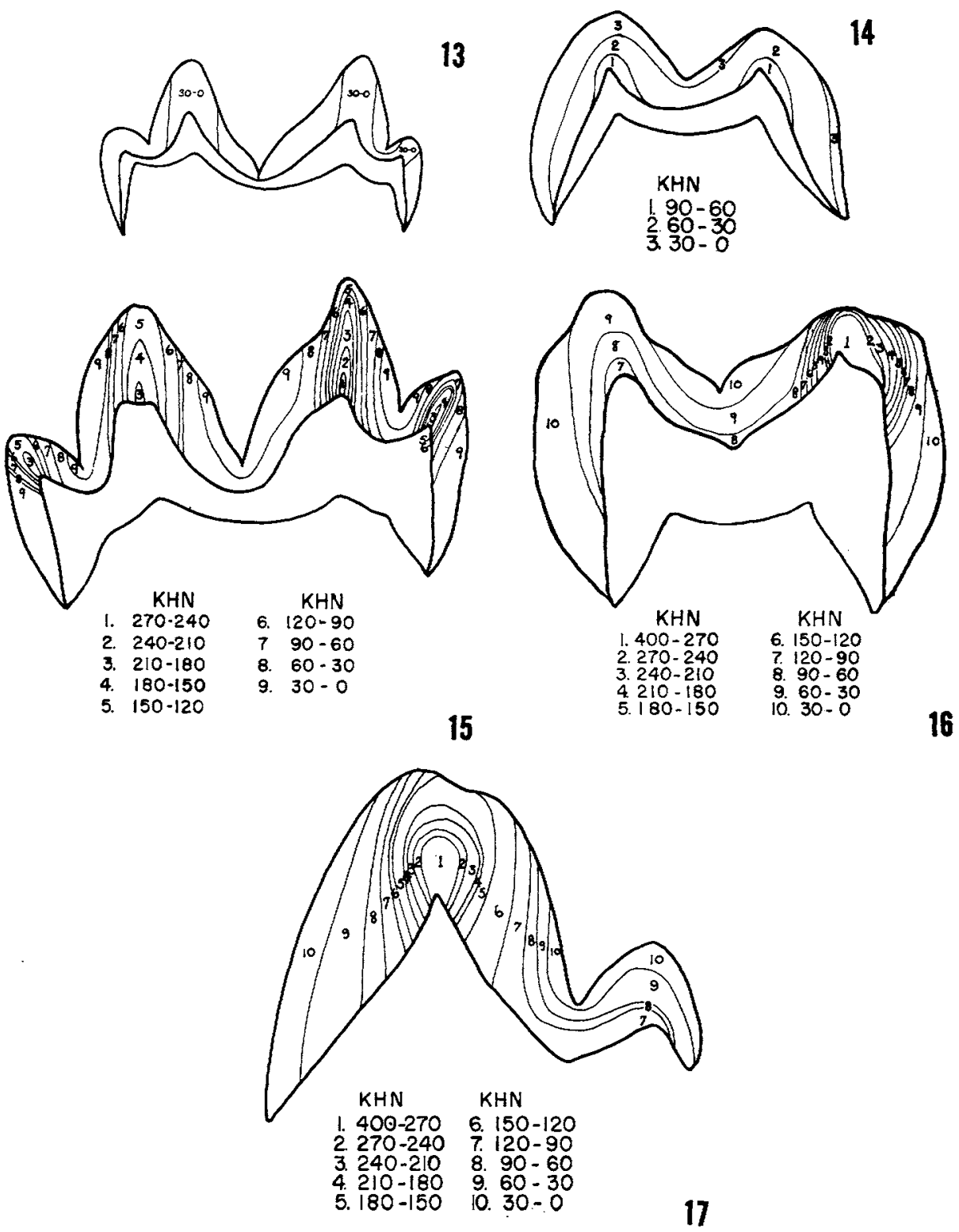

FIos. 13-17.-Fig. 13: Projection diagram of a mesiodistal section of young monkey molar, illustrating that the only enamel matrix of sufficient hardness to gain accurate indentation was at the tips of the cusps. The enamel in this area measured 0-30 KHN. (Orig. mag. $\times 13$.) Fig. 14: Projection diagram of a buccolingual section of a young human mandibular second molar, illustrating three areas of different hardness. Zone 1 near the dentino-enamel junction of the cusp tips was the hardest zone. This diagram and the microradiograph shown in Fig. 11 are of sections taken from the same tooth. (Orig. mag. $\times 13$.) Fig. 15: Projection diagram of a mesiodistal section of a monkey molar, indicating a more highly calcified tooth than that shown in Fig. 14. The hardness values, grouped in increments of $30 \mathrm{KHN}$, indicate the pattern of matrix formation. Zone 1 is in the lower limits of the range of adult hardness. (Orig. mag. $\times 13$.) Fig. 16: Projection diagram of a buccolingual section of a human maxillary permanent first molar, illustrating a slightly more highly calcified tooth than shown in Fig. 15. Zones 1 and 2 are in the range of adult hardness. (Orig. mag. $\times 13$.) Fig. 17: Projection diagram of a buccolingual section of a human permanent premolar, illustrating a tooth of hardness similar to that in Fig 16. (Orig. mag. $\times 13$.) 
enamel were within the range of adult hardness and that there was no incremental pattern of mineral density (Fig. 19).

It was then of interest to determine the extent of possible posteruptive mineralization. Eight human teeth-four pre-erupted and four erupted-were measured (Table 1). The mean hardness of enamel of the pre-erupted teeth was found to be $422 \pm 53$ $\mathrm{KHN}$ and that of enamel of the erupted teeth was $403 \pm 53 \mathrm{KHN}$. In a similar series of monkey teeth the mean hardness figures were 401.5 for pre-erupted enamel and 406.5 for erupted enamel. It would appear that very little mineral, if any, contributed
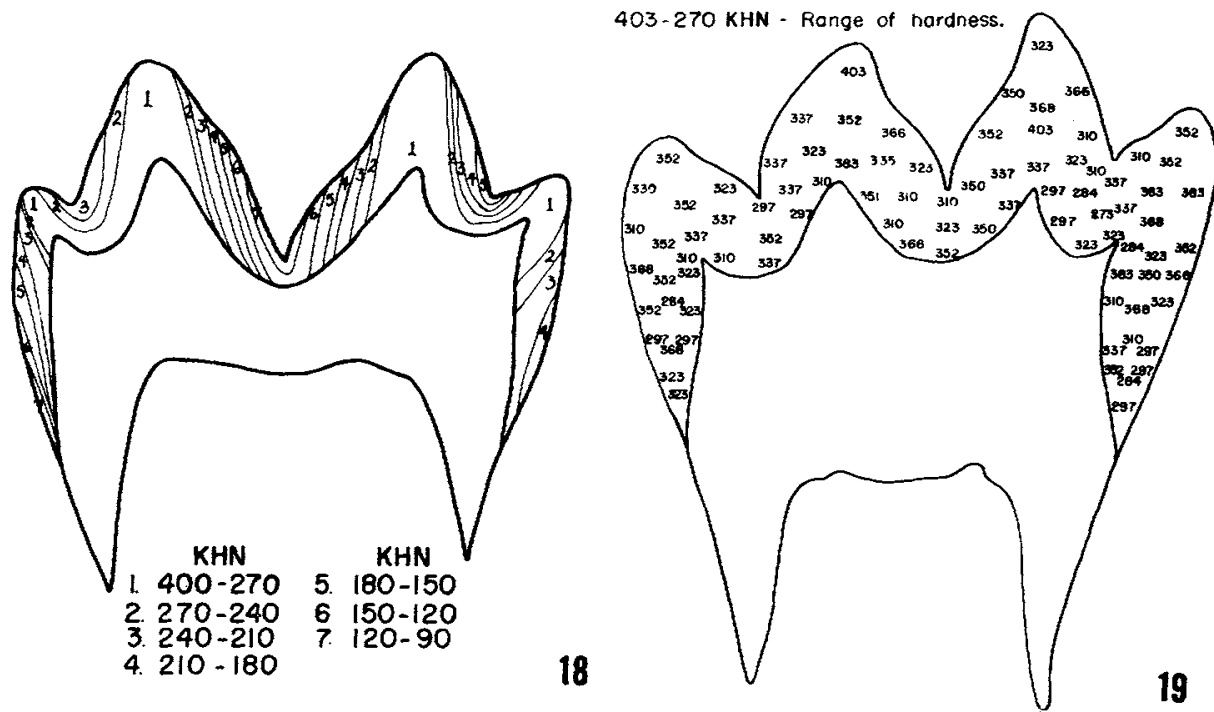

FIGs. 18-19.-Fig. 18: Projection diagram of a mesiodistal section of a monkey molar slightly more calcified than the tooth depicted in Fig. 17. The range of hardness values has decreased, with the least hard area measuring $90-120 \mathrm{KHN}$. Observe the incremental nature of the hardness pattern. This section was taken from the same tooth as that shown in Fig. 12. (Orig. mag. X13.) Fig. 19: Projection diagram of a mesiodistal section of a monkey molar in the intraosseous stage of eruption. All measurements of enamel are within the range of adult hardness, and there is no incremental pattern of hardness. (Orig. mag. $\times 13$.)

TABLE 1

Hardness Values of Human Permanent Teeth*

\begin{tabular}{|c|c|c|c|c|c|c|c|c|c|}
\hline \multirow{3}{*}{ Тоотн } & \multicolumn{4}{|c|}{ PRE-ERUPTED } & & \multicolumn{4}{|c|}{ ERUPTED } \\
\hline & \multicolumn{2}{|c|}{ Periphery } & \multicolumn{2}{|c|}{ All Other Areas } & \multirow{2}{*}{ Toотн } & \multicolumn{2}{|c|}{ Periphery } & \multicolumn{2}{|c|}{ All Other Areas } \\
\hline & $\begin{array}{l}\text { KHN } \\
\pm \text { S.D. } t\end{array}$ & $\begin{array}{c}\text { No. of } \\
\text { In- } \\
\text { denta- } \\
\text { tions }\end{array}$ & $\begin{array}{l}\text { KHN } \\
\pm \mathrm{S} . \mathrm{D}\end{array}$ & $\begin{array}{l}\text { No. of } \\
\text { In- } \\
\text { denta- } \\
\text { tions }\end{array}$ & & $\begin{array}{l}\text { KHN } \\
\pm \mathrm{S} . \mathrm{D} .\end{array}$ & $\begin{array}{l}\text { No. of } \\
\text { In- } \\
\text { denta- } \\
\text { tions }\end{array}$ & $\begin{array}{l}\mathrm{KHN} \\
\pm \mathrm{S} . \mathrm{D} .\end{array}$ & $\begin{array}{l}\text { No. of } \\
\text { In- } \\
\text { denta- } \\
\text { tions }\end{array}$ \\
\hline $\begin{array}{l}\text { 3d max. molar... } \\
\text { 3d mand. molar.. } \\
\text { 3d mand. molar. . } \\
\text { 3d mand. molar. . }\end{array}$ & $\begin{array}{l}428 \pm 54 \\
503 \pm 51 \\
453 \pm 62 \\
387 \pm 64\end{array}$ & $\begin{array}{l}32 \\
34 \\
26 \\
20\end{array}$ & $\begin{array}{l}386 \pm 57 \\
421 \pm 37 \\
409 \pm 57 \\
391 \pm 61\end{array}$ & $\begin{array}{l}80 \\
79 \\
87 \\
67\end{array}$ & $\begin{array}{l}\text { 1st max. molar... } \\
\text { 1st max. molar... } \\
\text { 1st mand. molar.. } \\
\text { 1st mand. molar.. }\end{array}$ & $\begin{array}{l}411 \pm 50 \\
433 \pm 57 \\
453 \pm 60 \\
417 \pm 51\end{array}$ & $\begin{array}{l}21 \\
21 \\
27 \\
24\end{array}$ & $\begin{array}{l}317 \pm 64 \\
398 \pm 50 \\
397 \pm 36 \\
397 \pm 53\end{array}$ & $\begin{array}{l}88 \\
59 \\
87 \\
60\end{array}$ \\
\hline Mean...... & $443+58$ & 28 & $402 \pm 53$ & 78 & Mean ...... & $429 \pm 55$ & 23 & $377 \pm 51$ & 74 \\
\hline
\end{tabular}

* All teeth trom different individuals; all readings considered.

t S.D. = Standard deviation. 
to an increased hardness posteruptively. It was also observed in all cases that the surfaces of both human and monkey pre-erupted and erupted teeth proved to be harder than the underlying enamel.

Microdissection and microsubstitution.-The ethylenediamine-treated specimens of human and monkey enamel were immersed in water and dissected under a stereomicroscope with finely drawn glass needles. It was found that the organic-free matrix of developing enamel which had not yet reached its adult thickness offered relatively little resistance to microdissection and that the individual rods or groups of calcified rods could be separated from each other with ease (Fig. 20). In the areas where the full thickness of the enamel had been attained, the rods could not be separated one from another. Decalcified developing enamel exhibited an opposite picture in which the rods were missing and the interrod substance was retained (Fig. 21).

The ethylenediamine-treated rods then were measured, and it was found that at the dentino-enamel junction the average diameter of enamel rods was $4.9 \mu$, whereas the diameter at the other end of the rod, near the surface of the enamel, measured $5.1 \mu$. It is not known whether the entire rod substance was present, however. This difference between the rod diameters at the dentino-enamel junction and at the periphery was noted to be consistent in various regions of the crown. However, the differences noted in rod diameter are within the range of experimental error.

A light-microscope study then was made of the series of developing crowns of human and monkey teeth in which the organic matter and water had been removed and replaced by polymers of small molecular size. After decalcification these specimens were examined by both reflected and transmitted light. Areas of high mineral content were found to contain very little plastic, whereas the less mineralized areas contained proportionately more plastic. The first area in enamel to exhibit noticeable mineralization was a narrow band along the dentino-enamel junction of the youngest tooth studied (Fig. 22). The next older specimen revealed a triangular area of more calcified enamel in the cusp tips, extending peripherally from the dentino-enamel junction for half the thickness of the enamel (Fig. 23). In an older specimen mineralization appears to have proceeded peripherally from the dentino-enamel junction not only at the cusp tips but along the sides of the cusps as well (Fig. 24). Mineralization, therefore, was advanced in all the areas of the earliest-deposited matrix. It can be observed that only small amounts of plastic, representing the organic interrod substance, were still present in the mineralized areas (Fig. 25). It is apparent that the location and degree of mineralization as ascertained by this technique correspond with those demonstrated by the microradiographic and microhardness determinations.

\section{DISCUSSION}

The appearance in the microradiographs of a strongly radiopaque line in enamel along the dentino-enamel junction confirms the findings of other investigators. $2,6,8-12,19,20$ The origin of this highly mineralized $35-50 \mu$-wide band may be from the tissue fluid of the pulp or the enamel organ or from both, and it is possible that it plays some role in succeeding enamel mineralization. This zone rapidly attains adult hardness, however, and therefore would inhibit the movement of minerals from the pulp to contribute to further enamel mineralization. An interesting factor is that two structurally different fiber types, each with crystals of a different size, are inter- 


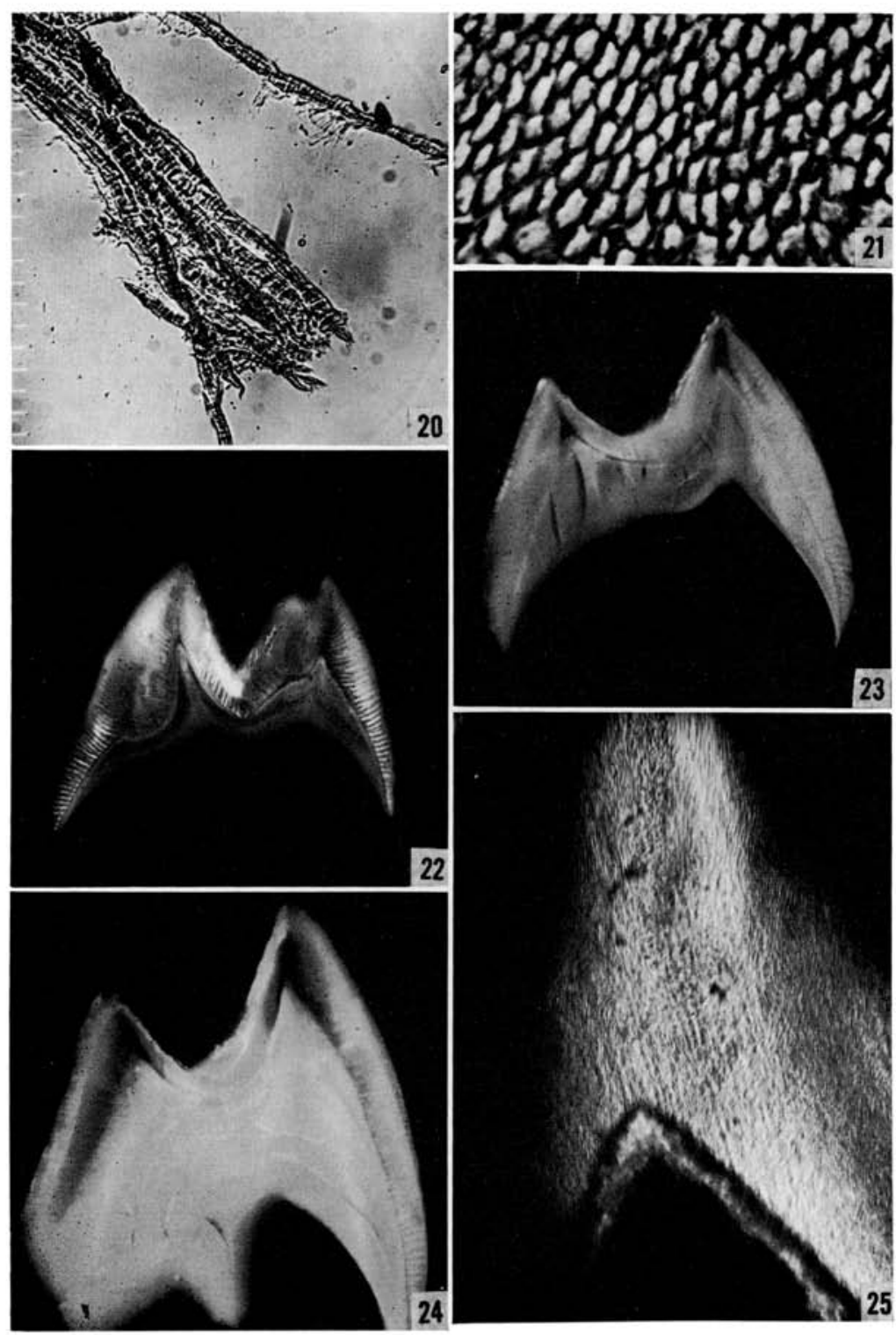

Figs. 20-25.-Fig. 20: Ethylenediamine-extracted enamel of a developing human tooth. During early calcification of the enamel matrix the rods could be separated easily, illustrating the large proportion of organic material in the interrod substance. Scale at left indicates that the rods are approximately $5 \mu$ in diameter. (Orig. mag. $\times 380$.) Fig. 21: Transmitted-light photomicrograph of decalcified young enamel of a developing human molar, illustrating the remaining interrod substance and the loss of calcified rod structure. Fig. 22: A reflected-light photomicrograph of a molar tooth after removal of organic matter and water and replacement by plastic of small molecular size. After decalcification, zones of high mineral (low plastic) concentration were revealed along the dentino-enamel junction. (Orig. mag. $\times 13$.) Fig. 23: A reflected-light photomicrograph of a slightly more highly mineralized tooth prepared in the same manner as that shown in Fig. 22. High mineral and low plastic concentration is seen clearly as the dark area extending peripherally from the dentino-enamel junction of the cusp tips. (Orig. mag. $\times 13$.) Fig. 24: A somewhat more calcified tooth prepared in the same manner as those in Figs. 22 and 23. Observe the lack of plastic, indicating high mineral content at the cusp tips and in the areas adjacent to the dentino-enamel junction along the sides of the cusps. (Orig. mag. $\times 13$.) Fig. 25: A high-magnification, transmitted-light photomicrograph of the right cusp tip shown in Fig. 23. The dark and light areas are reversed from the previous pictures, so that the dark areas in this transmitted-light picture are the plastic, representing the organic material and water. The light areas indicate high mineral, low plastic concentration where calcification is advanced, (Orig. mag. $\times 125$.) 
mingled in the inner portion of this zone. ${ }^{25}$ The approximately $50-\mathrm{A}$-wide fibrils of the enamel matrix ${ }^{26}$ have apatite crystals of $400-500 \mathrm{~A}$ in width, ${ }^{25}$ whereas the $600-\mathrm{A}$ wide collagen fibrils of dentin ${ }^{25}$ have several smaller crystals within the diameter of a single fiber ${ }^{26}$ Nowhere else in the human body is the specific nature of crystal formation on a specific fiber more clearly demonstrated than at the dentino-enamel junction. The present evidence that mineralization follows enamel matrix formation in a nearly incremental fashion suggests that time may be an important factor in the changes which the matrix fibers undergo before crystal nucleation and growth can occur. Changes in the matrix, such as loss of water and organic material ${ }^{32}$ or dehydration and condensation, ${ }^{33}$ are part of the mineralization process. However, other less easily determined mechanisms, such as phosphorylation, molecular transformation of sulfated polysaccharides, or electrostatic changes of the organic matrix, undoubtedly occur before mineralization can proceed. ${ }^{34,35}$

It has been noted that the interrod matrix is formed before the rod matrix ${ }^{25,36}$ and contains some mineral. ${ }^{37}$ However, the rod matrix becomes completely calcified before the interrod matrix calcifies. The finding of organic interrod substance after decalcification of mineralizing enamel has been noted by most dental histologists and was noted in the present study. Microradiographs showed that radiolucent areas between the rods during early mineralization were wider than such areas in more completely calcified enamel. It is possible that if the rod calcifies from the center peripherally and if it is not completely calcified at this stage of development, the area between the calcified portion of the rods is in part uncalcified rod substance, as well as interrod substance. Figures 9 and 10 would appear to support the theory that the rods calcify from the center peripherally. Microdissection of organic-free developing enamel indicated that the interrod substance must have contained a relatively large proportion of organic matter which was dissolved by the ethylenediamine, thus allowing separation of the rods. The rods themselves, however, were sufficiently calcified that, in spite of the loss of their organic matrix, their general morphology was retained. This observation is significant in view of the following. First, in the development of enamel, the interrod space is the logical route for calcium and phosphate ions to diffuse along and around the entire length of the developing enamel rod, thus allowing the rod matrix to calcify from the dentino-enamel junction peripherally. Then, after the enamel rods are completely calcified, the interrod matrix becomes completely calcified. Second, in caries of enamel the interrod substance is the first area to be altered. ${ }^{38-41}$ It is of interest that the steps in enamel destruction are the same as those in enamel formation but in reverse order. It is therefore important now to concentrate investigative effort on determining the basic differences in the structure of the mineralized rod and interrod substances. Differences in solubility of these two may be due to such factors as the difference in degree of calcification of the rod and interrod substances, higher carbonate concentration of the interrod substance, and/or the difference in orientation of the interrod fibers and thus the crystal structure as compared with that of the enamel rod. ${ }^{25,36}$ The sum of these differences results in a mineral-fiber bond that is more susceptible to initial acid attack. It is difficult to explain why the sections in the present study exhibited increased radiopacity along the incremental lines or alternate Schreger bands. Such differences in radiodensity in these areas have been reported. ${ }^{10,20,42}$ There is, perhaps, a different explanation for each of these observed variations. The 
increased radiodensity of the incremental lines may represent a phase in the mineralization process indicating an area of increased crystal growth. This relative difference in mineral density between the incremental lines and adjacent enamel matrix gradually disappears as mineralization proceeds. This observation in the present study confirms the findings of Allan. ${ }^{10}$ Therefore, the incremental lines of Retzius are developed initially as zones of higher mineral content at least as high as that of adjacent areas. Gustafson, ${ }^{43}$ who carried out extensive studies on adult human enamel, noted that these lines are not zones of lower mineral content, as some authors ${ }^{23,24}$ have contended. The difference in X-ray absorption in alternate Schreger bands could possibly be due to the amount of uncalcified interrod substance penetrated by the X-rays.

The technique of microhardness has proved successful in illustrating that the complement of mineral in adult enamel is laid down in an incremental or nearly incremental manner following the pattern of matrix formation. There is, therefore, no possibility of a secondary maturation process at right angles to the incremental pattern which has been said to account for three-quarters of the mineral content of enamel. ${ }^{24}$ Weinmann, Wessinger, and Reed, ${ }^{18}$ in precise analyses of the calcium content of the crown tip and the middle and cervical areas of developing enamel, undoubtedly would have illustrated this if it had been technically possible for them to obtain samples of enamel from both the dentino-enamel junction and the periphery of enamel in each of those three areas. The artificial boundaries separating matrix formation and calcification therefore should be eliminated, as well as the term "maturation of enamel" which has been used to imply a secondary process of mineralization. We should, instead, orient our thinking to the intimate relationship of the fibrous matrix and mineral, in order to gain further information on the complex mechanisms involved in enamel crystal formation and growth.

Several observations concerning dentin formation were made during the course of this study. Although dentin matrix formation is known to begin prior to enamel formation, ${ }^{23,} 24$ dentin matrix is deposited much more slowly than the enamel matrix in the young developing crown (Figs. 3-8). After enamel matrix deposition is complete, the thickness of the dentin equals and then exceeds that of the enamel (Fig. 18). This finding obviously does not support the daily appositional rhythm described by Schour, ${ }^{23}$ since the two types of matrices must have different rates of incremental deposition. It was also noted during the microhardness studies that young, developing dentin near the dentino-enamel junction was only about half as hard as adult dentin. Therefore, further mineralization than that which occurs along the predentin-dentin calcification front must take place. This supports the recent autoradiographic findings of Kumamoto and Leblond ${ }^{28}$ on interstitial calcification of the dentin.

The enamel of human and monkey erupted molars was not significantly harder than that of the pre-erupted molars. The mean hardness value obtained from 387 measurements in four erupted human first molars was found to be $403 \pm 53$, which is within the range of the findings of Craig and Peyton ${ }^{31}$ of $343 \pm 23$ KHN. The mean hardness value of $422 \pm 55$ obtained from 425 measurements of the four pre-erupted human third molars would seem to indicate that they are slightly harder. This difference, however, is not significant in view of the size of the standard deviation. If there was a definite posteruptive increase or decrease in the mineral content of the tooth, it was believed to be too small to be identified in the present analysis. It is probable that 
microhardness tests cannot give the final answer to the question of posteruptive mineralization unless an extremely large sample of teeth is studied. The range of hardness values is so great in comparing one crown with another and even within a single crown that the relatively small amount of mineral that may be deposited posteruptively cannot be identified as such. On the other hand, both the pre-erupted and the erupted teeth studied showed a definite increase in hardness at the enamel surface. This characteristic in adult erupted teeth has been noted by a number of investigators. ${ }^{44-47}$ It has been observed also in microradiographs of developing enamel. $8,10,12,29$ In the present study, microhardness tests confirmed the findings of increased hardness at the enamel surface in both pre-erupted and erupted teeth. This would point to the conclusion that enamel surface hardness is due partially, if not entirely, to pre-eruptive developmental processes.

The technique ${ }^{30}$ for substituting small-molecular-size polymer for the previously removed organic material and water in the series of developing crowns substantiated the evidence offered by the microradiographic and microhardness tests that teeth calcify from the dentino-enamel junction peripherally.

Although there are some slight differences in interpretation of the findings of recent investigations as to whether enamel mineralization occurs in one phase ${ }^{8}$ or in several phases, ${ }^{11,12}$ there is agreement among these investigators that the pattern of mineralization of enamel follows closely that of matrix formation. Therefore, the area of initial matrix formation at the dentino-enamel junction of the cusp tip is the site of the first mineralization and the cervical area is the site of the last in every case. The findings of the present investigation further support these conclusions by accounting for the distribution of enamel mineral over the entire pre-eruptive period of enamel calcification.

\section{SUMMARY}

An investigation using microradiographic, microhardness, microdissection, and microsubstitution techniques was made to gain information about pre- and posteruptive calcification of enamel in 72 human and Rhesus monkey teeth. The following observations were made.

The general pattern of enamel matrix calcification followed and was closely related to the pattern of matrix formation, in disagreement with the theories of two-stage matrix formation-maturation processes.

A band along the dentino-enamel junction reached adult hardness during early matrix formation. The remainder of the matrix exhibited a gradient in radiopacity and hardness from the dentino-enamel junction peripherally which followed the same or a very similar pattern as the incremental pattern of enamel matrix formation. The enamel-rod matrix calcified before the interrod substance, the latter thus presenting pathways for diffusion of tissue fluid containing calcium-phosphate ions, during the mineralization process.

The appearance of radiopacity along the incremental lines was a characteristic of early mineralization. No evidence of a posteruptive increase in mineral content was demonstrated by the microhardness technique. Surface hardness was a characteristic of unerupted as well as erupted teeth. 
The authors wish to express their sincere appreciation to Miss Elizabeth Haley and Dr. Donald Strachan for assistance in preparation of the specimens and evaluation of the results and to $\mathrm{Mr}$. Herbert Andre for preparation of the photomicrographs.

\section{REFERENCES}

1. HaLs, E. Fluorescence Microscopy of Developing and Adult Teeth. Oslo, Norway: Norwegian Academic Press, 1953.

2. Engfeldt, B., and Hammarlund-Essler, E. Studies on Mineralized Dental Tissues. IX. A Microradiographic Study of the Mineralization of Developing Enamel, Acta Odont. Scand., 14:273, 1956.

3. EBNER, V. voN. Über die histologischen Veränderungen des Zahnschmelzes während der Erhartung insbesondere beim Menschen, Arch. f. mikr. Anat., 67:18, 1906.

4. Schmidr, W. J. Doppelbrechung und Feinbau des Zahnschmelzes. Sitzber. Niederrhein, Ges. Natur-u. Heilk., Naturwiss., Abt. P, pp. 1-19, 1923.

5. Chase, S. W. The Nature of the Enamel Matrix at Different Ages, J.A.D.A., $22: 1343,1935$.

6. HARDERS-STEINHAUSER, M. Die Erhartung des Zahnschmelzes nach polarisationsoptischen Untersuchungen, $Z$. Zellforsch., $28: 274,1938$.

7. Nuckolis, J., Leicester, H. M., and Dienstenn, B. Amelogenesis, J. Am. Col. Den., 14:118, 1947.

8. Hammarlund-Essler, E. A Microradiographic-microphotographic and X-Ray Diffraction Study of Human Developing Enamel, Trans. Roy. Schools Dentistry, Stockholm and Umea, No. 4, p. 15, 1958.

9. Allan, J. H. Mineralization of Human Enamel, Nature, 180:1362, 1957.

10. - Investigation into the Mineralization Pattern of Human Dental Enamel, J. D. Res., $38: 1096,1959$.

11. CrabB, H. S. M., and DarLing, A. I. Observation on the Pattern of Mineralization of Human Dental Enamel, J. D. Res., $37: 750,1958$ (abstr.).

12. Crabe, H. S. M. The Pattern of Mineralization of Human Dental Enamel, Proc. Roy. Soc. Med., $\mathbf{5 2}: 118,1959$.

13. Beust, T. B. von. Intrafollicular Enamel Development, J.A.D.A., 15:2021, 1928.

14. Metranby, M. Diet and Teeth: An Experimental Study. I. Dental Structures in Dogs, Spec. Rept. Ser. Med. Res. Council, London, No. 140, 1929.

15. - Diet and Teeth. III, ibid., No. 191, 1934.

16. KITchrn, P. C. Some Observations on Enamel Development as Shown in the Mandibular Incisor of the White Rat, J.D. Res., 13:25, 1933.

17. Diamond, M., and Wetnmann, J. P. The Enamel of Human Teeth. New York: Columbia University Press, 1940.

18. Weinmann, J. P., Wessinger, G. D., and Reed, G. Correlation of Chemical and Histological Investigations on Developing Enamel, J.D. Res., $21: 171,1942$.

19. Glock, G. E., Mellanby, H., Melianby, M., Murray, M. M., and Thewlis, J. The Study of the Development of the Enamel in Dogs, J. D. Res., 21:183, 1942.

20. Applebaum, E. Grenz Ray Studies of Enamel Matrix Formation and Calcification, J. D. Res, $22: 7,1943$.

21. Marsland, E. A. A Histological Investigation of Amelogenesis in Rats. II. Maturation, Brit. D. J., $92: 109,1952$.

22. Belanger, L. F. The Mineralization of Rat Enamel in the Light of $\mathrm{Ca}^{45}$ Autoradiography and Microincineration, J. D. Res., 36:593, 1957.

23. Schour, I. Noyes Oral Histology and Embryology. 8th ed. Philadelphia: Lea \& Febiger, 1960.

24. ORban, B. J. Oral Histology and Embryology. St. Louis, Mo.: C. V. Mosby Co., 1957.

25. Watson, M. L., and Avery, J. K. The Development of the Hamster Lower Incisor as Observed by Electron Microscopy, Am.J. Anat., $95: 109,1954$.

26. Frank, R. M., Sognnaes, R. R., and Kern, R. Calcification of Dental Tissues with Special Reference to Enamel Ultrastructure, in Calcification in Biological Systems, p. 163. Washington, D.C.: American Association for the Advancement of Science, 1960.

27. Leblond, C. P., Belanger, L. F., and Greutich, R. C. Formation of Bones and Teeth as Visualized by Radioautography, Ann. N.Y. Acad. Sci., 60:631, 1955.

28. Kumamoto, Y., and LebLond, C. P. Radioautographic Study of Mineralization of Growing Teeth with Labeled Calcium, J. D. Res., 35:147, 1956. 
29. Crabb, H. S. M., and Darling, A. J. The Gradient of Mineralization in Developing Enamel, Arch Oral Biol., 2:308, 1960.

30. Knapp, D. E., Avery, J. K., and Costich, E. R. A Technique for the Study of the Internal Structure of Calcified Tissues, J. D. Res., 37:880, 1958.

31. Cratg, R. G., and Peyton, F. A. The Microhardness of Enamel and Dentin, J. D. Res., 37:661, 1958.

32. Dearins, M. Changes in the Ash, Water and Organic Content of Pig Enamel during Calcification, J.D. Res., $21: 429,1942$.

33. Sognnaes, R. F., Scotr, D. B., Ussing, M. J., and Wyckoff, R. W. G. Electron Microscopy of the Enamel of Teeth in Various Stages of Development, J. D. Res., 31:85, 1952.

34. Weidmann, S. M. Review of Modern Concepts on Calcification, Arch. Oral Biol., $1: 259,1959$.

35. GLIMCHER, M. M. Specificity of the Molecular Structure of Organic Matrices in Mineralization, in Calcification in Biological Systems, p. 421, Washington, D.C.: American Association for the Advancement of Science, 1960.

36. Qutalex, M. B. Electron Microscopy of Developing Enamel Matrix in the Syrian Hamster, J. D. Res., 28:180, 1959.

37. Nyten, M. U., and ScotT, D. B. Electron Microscopic Studies of Odontogenesis, J. Indiana D. A., 39:406, 1960.

38. Hais, E., MoRCh, T., and SAND, H. Effect of Lactate Buffers on Dental Enamel in Vitro as Observed in Polarizing Microscope, Acta Odont. Scand., 13:85, 1955.

39. Guzman, D., Brudevot., F., and Mermagen, H. A Soft Roentgen-Ray Study of Early Carious Lesions, J.A.D.A., 55:509, 1957.

40. Newbrun, E., Brudevold, F., and Mermagen, H. A Microradiographic Evaluation of Fissures and Grooves, J.A.D.A., 58:26, 1959.

41. - A Microroentgenographic Investigation of Demineralized Enamel, Comparing Natural and Artificial Lesions, Oral Surg., Oral Med., Oral Path., 13:576, 1959.

42. Apptebaud, E. Grenz Ray Studies of the Calcification of Enamel, J. D. Res., 17:181, 1938.

43. Gustafson, G. The Structure of Human Dental Enamel, Odont. Tskr., Vol. 53, Suppl., 1945.

44. KarLstrom, S. Physical, Physiological and Pathological Studies of Dental Enamel with Special References to the Question of Its Vitality. Stockholm: A. B. Fahlcrantz Boktryckeri, 1931.

45. Hodge, H. C., and McKay, H. The Microhardness of Teeth, J.A.D.A., 20:227, 1933.

46. Atkinson, H. F., and Saunsbury, P. An Investigation into the Hardness of Human Enamel, Brit. D. J., 94:249, 1953.

47. Caldwell, R. C., Muntz, J. L., Gilmore, R. W., and Pigman, W. Microhardness Studies of Intact Surface Enamel, J. D. Res., 36:732, 1957. 